\title{
PENGEMBANGAN VIRTUAL REALITY SEBAGAI MEDIA PEMBELAJARAN SISTEM TATA SURYA
}

\author{
Muhammad Abid Darojat, Saida Ulfa, Agus Wedi \\ Teknologi Pendidikan, Fakultas Ilmu Pendidikan, Universitas Negeri Malang. \\ Jl. Semarang No.5, Malang, 65145, Indonesia. \\ abidarojat87@gmail.com
}

Article History

Received: 18 Maret 2021, Accepted: 17 April 2021, Published: 20 Februari 2022

\begin{abstract}
Abstrak
Penelitian dan pengembangan ini bertujuan untuk menghasilkan produk berupa media pengembangan virtual reality sebagai media pembelajaran sistem tata surya pada materi susunan tata surya. Penelitian Research and Development $(R \& D)$ ini menggunakan metode Sadiman yang tahapannya sesuai dengan produk yang akan dikembangkan. Metode sadiman memiliki beberapa tahapan seperti analisis kebutuhan, perumusan tujuan pembelajaran, perumusan materi, perumusan alat ukur keberhasilan, penyusunan naskah media, produksi media, validasi, media siap pakai. Didalam pembelajaran media virtual reality ini digunakan sebagai pelengkap bahan ajar untuk mata pelajaran IPA. Hasil dari uji kelayakan produk yang telah dilaksanakan pada ahli media, ahli materi, dan siswa mendapatkan banyak tanggapan positif, sehingga dapat disimpulkan bahwa media virtual reality sistem tata surya ini layak digunakan dalam pembelajaran. Media ini memberikan kemudahan pada siswa dalam menganalisa susunan tata surya dan memberikan daya tarik untuk siswa sehingga timbul rasa ingin belajar yang meningkat. Akan tetapi untuk penggunaannya harus menggunakan gawai yang sudah memiliki kemampuan gyroscope.
\end{abstract}

Kata kunci: Smartphone; Virtual Reality; IPA

\begin{abstract}
This research and development aims to produce a product in the form of virtual reality development media as a learning medium for the solar system on the material of the solar system. Thisresearch Research and Development $(R \& D)$ uses the Sadiman method, which stages are in accordance with the product to be developed. The sadiman method has several stages such as needs analysis, formulation of learning objectives, formulation of material, formulation of measuring tools for success, preparation of media scripts, media production, validation, ready-to-use media. In this virtual reality media learning is used as a complement to teaching materials for science subjects. The results of the product feasibility test that have been carried out on media experts, material experts, and students have received many positive responses, so it can be concluded that the media virtual reality system of the solar system is suitable for use in learning. This media makes it easy for students to analyze the arrangement of the solar system and provides an attraction for students so that an increased sense of desire to learn arises. However, to use it, you must use a device that already has the capability of a gyroscope
\end{abstract}

Keyword: Smartphone; Virtual Reality; Natural Science 


\section{PENDAHULUAN}

Perkembangan teknologi pada masa sekarang ini didukung oleh tampilan-tampilan grafis yang semakin canggih. Kemajuan teknologi ini memiliki pengaruh yang sangat besar terhadap keberlangsungan hidup manusia. Pendidikan merupakan salah satu aspek yang bisa memberikan perubahan dalam kehidupan. Pendidikan merupakan aspek yang sangat penting bagi setiap negara untuk dapat berkembang pesat. Negara yang hebat akan menempatkan pendidikan sebagai prioritas pertamanya, karena dengan pendidikan kemiskinan pada rakyat di negara tersebut bisa berubah menjadi kesejahteraan (Megawanti, 2015). Pendidikan pada masa sekarang ini harus disesuaikan dengan perkembangan zaman dikarenakan dengan mengikuti zaman bisa membuat siswa semakin termotivasi dalam belajar. Berbarengan dengan muncul perkembangan teknologi terlebih lagi pada internet berisi sistem informasi, mode pembelajaran pada sekarang ini sudah memaksimalkan teknologi informasi yang ada baik dari sekolah dasar hingga perguruan tinggi (Suwastika, 2018). Pemakaian media pembelajaran di proses pembelajaran daring bisa memberikan efek rasa ingin belajar bertambah dan menganugerahkan impak psikologis kepada pebelajar (Indriyani, 2019).

Pada perkembangan teknologi yang sudah ada pada zaman sekarang terjadi pada video pembelajaran. Penggunaan komponen animasi di dalam sebuah video pembelajaran dapat memberikan efek menarik perhatian, serta merangsang pemikiran pebelajar agar lebih berkesan, hal ini akan membantu untuk mengurangi proses beban kognitif pebelajar dalam menerima suatu materi pelajaran atau wejangan yang akan diamanatkan dari pembelajar (Luhulima et al., 2018). Video merupakan gambar yang bergerak. Jika wujud pada animasi adalah buatan, maka wujud pada video virtual reality buatan tetapi menciptakan kesan nyata pada penonton. Dengan kemajuan teknologi dan perkembangan sosial budaya di negeri ini pada masa sekarang, menyimak video merupakan kegiatan yang mudah dikerjakan oleh semua warga (Fadhli, 2016).

Dalam pembelajaran di sekolah terdapat mata pelajaran Ilmu Pengetahuan Alam yang di ajarkan pada tingkat Sekolah Menengah Pertama. Ilmu Pengetahuan Alam merupakan kepandaian untuk menafsirkan jagat raya secara sistematik serta menngembangkan penafsiran sains mengenai fenomena jagat raya diluapkan berbentuk fakta yang terbukti kevalidannya. Dan bisa memberi kajian dengan berharap pebelajar bisa memiliki pengalaman langsung dengan tingkatan sistematis menjalani beraneka ragam ttahapan logis, dan berujung kepada seonggok penemuan terbaru perihal jagat raya agar terkabul tujuan pembelajar pada pebelajar (Ariyanto, 2016). Secara garis besar, IPA mengantongi tiga elemen, yaitu: yang pertama proses ilmiah, semacam mengidentifikasi, mengklasifikasi, menebak, merancang, dan menjadwalkan percobaan; yang kedua produk ilmiah, bagai asas, rangrangan, hukum, dan teori, serta yang ketiga sikap ilmiah, bagai tindakan mencari tahu, hati-hati, optimal, dan jujur. Ketiga elemen itu silih berkaitan satu sama lain. Proses saintifik (kapabilitas proses) akan memerankan wahana pengait antara pengembangan konsep dan pengembangan sikap serta nilai. Dengan demikian, IPA bukanlah sekedar kumpulan kemahiran atau materi saja (Noviana, 2017). Pembelajaran IPA bertujuan untuk memanaskan keingintahuan pebelajar, meluaskan kapabilitas berpikir saintifik. Pembelajaran IPA tidak berpatokan terhadap draf, melainkan mempersembahkan keahlian secara nyata dalam perluasan produk, proses, aksi saintifik, yang semakin melebar bisa membuat literasi saintifik (Kelana \& Pratama, 2019).

Pada mata pelajaran IPA terdapat materi tata surya. Di materi tersebut diharapkan pebelajar mampu menganalisa susunan tata surya. Perlu memberikan alat yang bisa berdampak positif untuk dipergunakan sebagai perantara komunikasi dalam kegiatan pembelajaran (Sihkabuden, 2011). Berdasarkan pembelajaran yang telah dilakukan media yang dimanfaatkan pembelajar berupa buku paket yang berisi gambar yang kurang memberikan gambaran mengenai materi secara detail 
maka pebelajar kesulitan selama menganalisis sistem tata surya dan juga kurang untuk memompa semangat belajar dari pebelajar yang sangat bosan terhadap media buku paket. Dengan begitu tujuan pembelajaran sulit untuk dicapai.

Media video virtual reality yang berisikan objek susunan tata surya. Virtual reality merupakan teknologi untuk menyulut user dapat berhubungan atau merasakan suatu peristiwa pada kawasan yang dioperasikan oleh komputer (computer-simulated environment), suatu kawasan tersebut sebenarnya hanya tiruan atau benar-benar suatu zona yang cuma ada dalam imaginasi (Zuli, 2018). Pendapat Neelakantam \& Pant (2017:1) virtual reality ialah gabungan dari perangkat keras yang dikombinasikan, digunakan untuk membuahkan hasil simulasi tentang lingkungan. Kawasan yang dihasilkan merupakan replica atau tiruan dari kawasan yang sebenarnya dengan pengaturan tiga dimensi, gambar dan suara (Sinambela et al., 2018). Pada virtual reality terdapat empat elemen dasar yang pertama virtual environment wajib membuahkan hasil zona virtual ini ialah esensi dasar virtual reality, kedua virtual presence ialah pengguna harus merasakan kehadiran zona virtual yang sudah diciptakan, ketiga sensory feedback diartikan virtual reality harus memberikan respon balik terhadap pengguna, ke empat interactivity yang dimaksudkan disini virtual reality harus mampu menanggapi tindakan pengguna terhadap zona virtual yang tercipta (Mihelj et al., 2014).

Dari penjelasan yang ada diatas maka dibuatlah pengembangan virtual reality. Virtual reality ialah satu media yang membuahkan kawasan virtual yang berefek user merasakan kejadian atau peristiwa yang sedang terjadi pada media tersebut. Media ini diposisikan sebagai pelengkap pada pembelajaran yang terjadi di dalam kelas daring (Nisrina et al., 2017). Pengembangan media menggunakan aplikasi unity berguna untuk membuat kawasan virtual yang diharapkan. Video virtual ini bisa diakses dengan gampang melalui youtube asalkan memiliki internet serta gadget $V R$, (S-VR). S-VR ialah perabot kacamata optic yang cuma mempunyai dua kaca cembung pada kacamata VR itu. Untuk pendayagunaan S-VR, dibantu beserta memanfaatkan gadget yang mempunyai fitur Gyroscope dalam perangkatnya (Syafril, 2019). Media yang dikembangkan ini termasuk mobile learning dikarenakan dalam pemanfaatannya menggunakan unit mobile (Pratama et al., 2018).

Dari permasalahan yang ada pada latar belakang maka dikembangkanlah virtual reality sebagai media pembelajaran pada mata pelajaran Ilmu Pengetahuan Alam materi sistem tata surya. Virtual reality dapat memudahkan siswa dalam menganalisis susunan tata surya dengan bantuan kacamata VR ini rasa ingin belajar siswa meningkat.

\section{METODE}

Jenis penelitian yang diterapkan merupakan penelitian dan pengembangan atau research and development $(R \& D)$ yang dikembangkan oleh Sadiman (2010). Model pengembangan(Sadiman, 2010) ini dipilih karena sesuai untuk di aplikasikan pada media virtual reality yang akan di kembangkan. Ada beberapa tahapan dalam model pengembangan Sadiman (2010) yang meliputi : analisis kebutuhan, perumusan tujuan pembelajaran, perumusan materi, perumusan alat ukur keberhasilan, penulisan naskah media, produksi media, validasi, revisi, media siap pakai.

Uji kelayakan produk dilakukan kepada ahli media, ahli materi, dan 3 orang siswa secara langsung didalam kelas. Pengambilan data menggunakan angket yang berjumlah masing-masing 10 butir untuk ahli media, ahli materi, dan 3 siswa. Angket yang dibuat memiliki tiga aspek yaitu aspek kemenarikan, aspek kemudahan, dan aspek motivasi. Didalam angket berisi empat opsi respon yang bisa dipilih yaitu sangat setuju, setuju, kurang setuju, dan tidak setuju. jika mendapatkan banyak respon sangat setuju dan setuju maka bisa dimaknakan peneletian berhasil dikarenakan kedua opsi tersebut termasuk dalam tanggapan positif. 


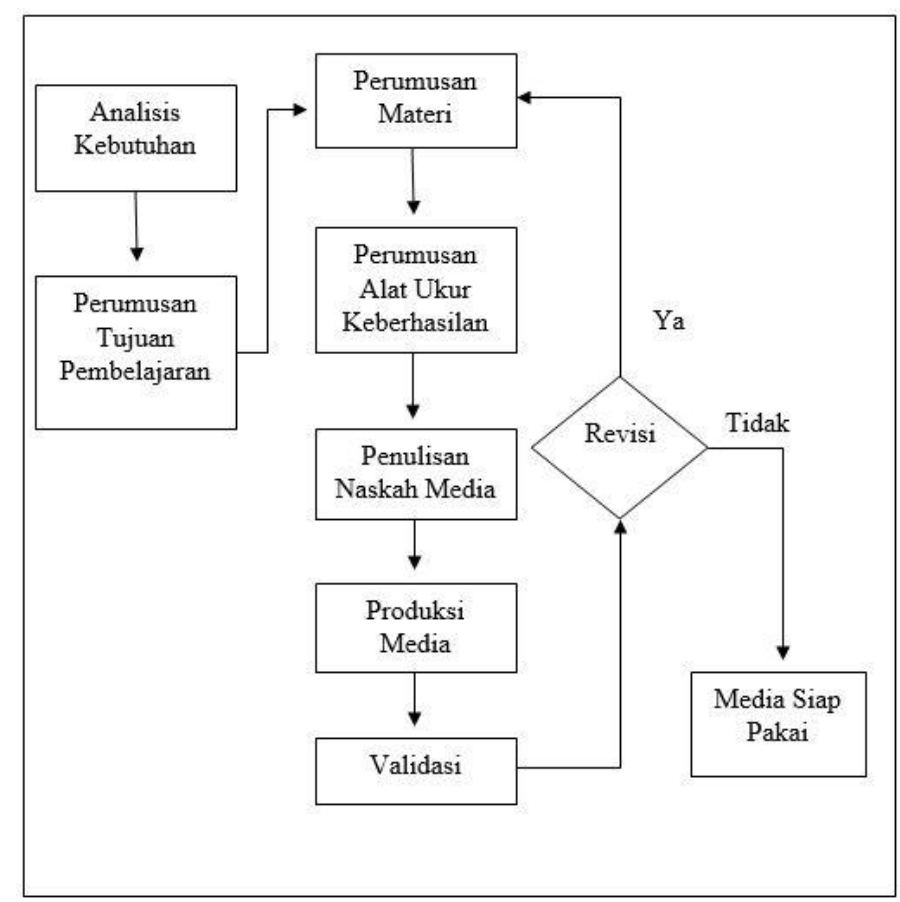

Gambar 1. Model R\&D (Sadiman, 2010)

\section{HASIL}

Pada penelitian ini uji kelayakan produk dilakukan oleh ahli media dan ahli materi yang mempunyai keahlian dibidang yang sesuai dengan produk ini. Kemudian ujicoba pada siswa untuk mengetahui keberhasilan tujuan media virtual reality.

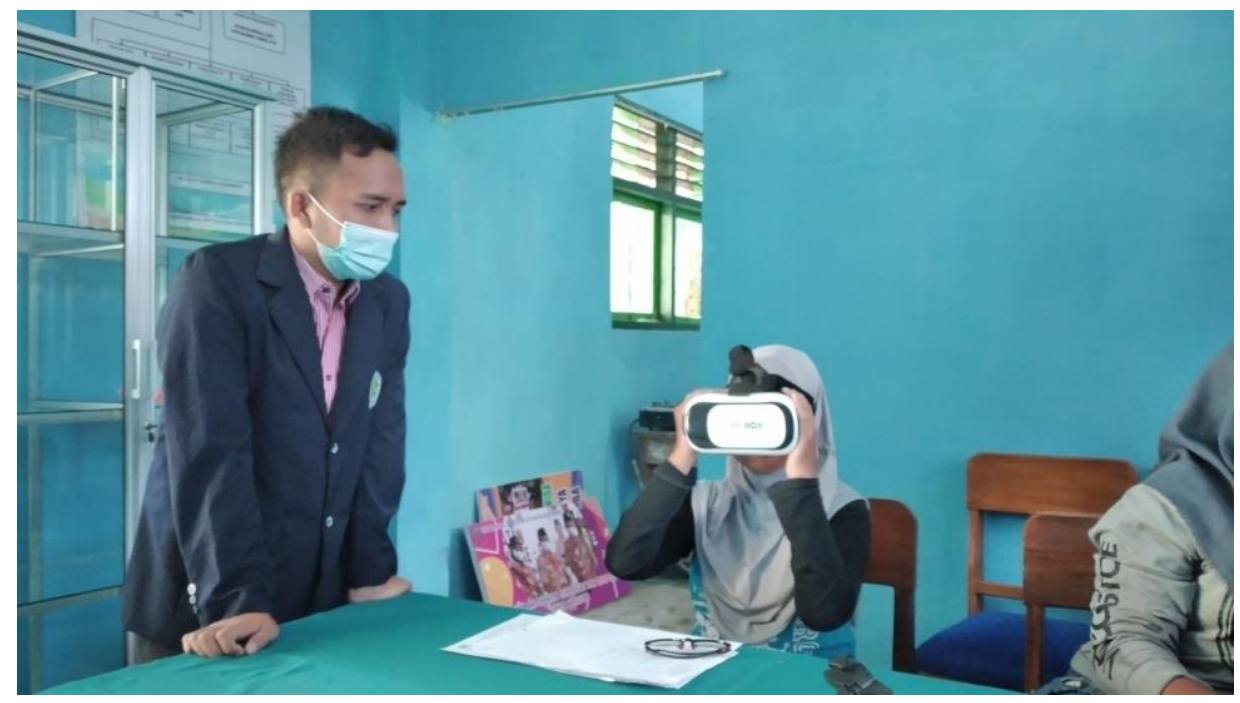

Gambar 2. Ujicoba Produk

Gambar 2 menunjukkan uji coba produk yang dilakukan kepada 3 siswa untuk mengetahui keberhasilan media virtual reality ini. Uji coba ini dilaksanakan pada masa pandemi COVID 19 tahun 2020 di sekolah. Perangkat VR Box yang digunakan hanya 1, sehingga bergantian antar siswa dalam uji coba pemanfaatannya. 


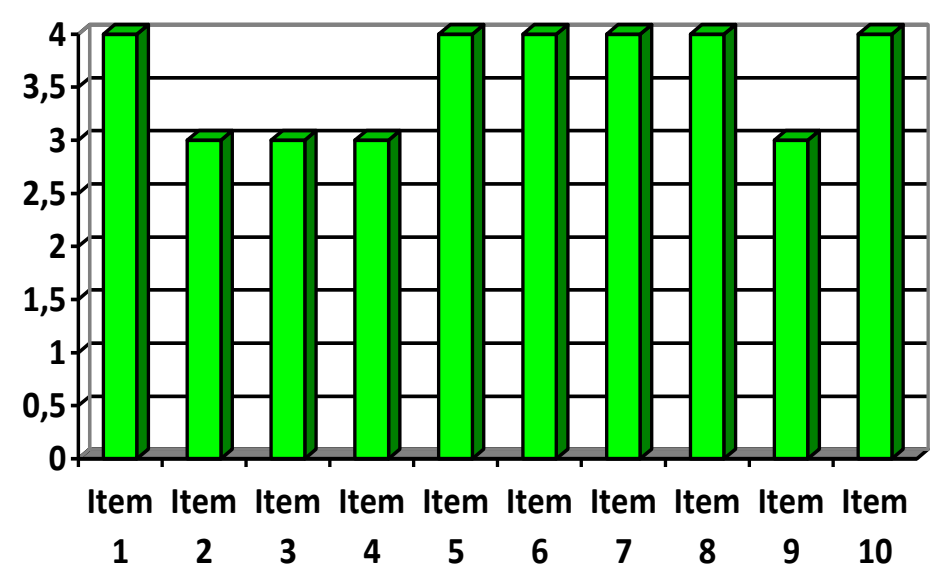

\section{Grafik 1. Hasil Tanggapan Ahli Media}

Pada grafik 1 ditampilkan hasil tanggapan yang telah didapatkan. Dengan hasil analisis persentase respon positif terhadap media sebesar $100 \%$, persentase SS 60\%, respon S sebesar 40 $\%$, mean 3,6, median 4, dan modus 4. Dari hasil tersebut dapat disimpulkan bahwa media layak digunakan dalam pembelajaran.

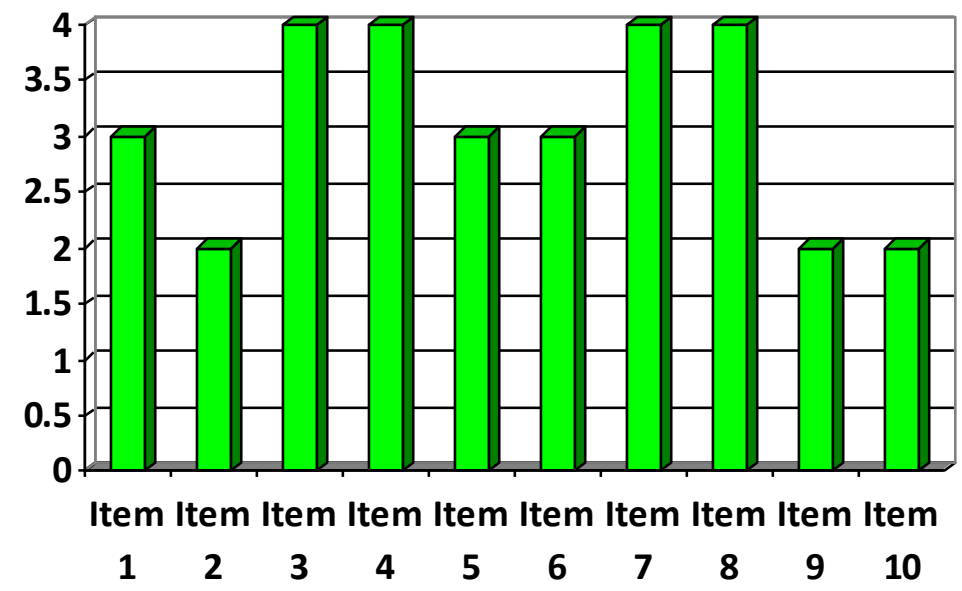

\section{Grafik 2. Hasil Tanggapan Ahli Materi}

Berdasarkan grafik 2 disajikan hasil respon yang telah didapatkan. Dengan hasil analisis persentase respon positif sebesar 70\%, persentase SS 40\%, persentase S 30\%, mean 3,1, median 3, dan modus 4. Dari hasil tersebut dapat disimpulkan bahwa media layak digunakan dalam pembelajaran.

Berdasarkan tabel 1 dibawah ini disajikan hasil ujicoba yang dilakukan pada 3 siswa di sekolah Miftahul Huda Blitar. Mendapatkan hasil tanggapan dengan rata-rata 3,57 dari nilai maksimal 4. Dengan rincian siswa memilih tanggapan sangat setuju berjumlah 18 sedangkan yang memilih setuju berjumlah 12 tanggapan. Dari rincian tersebut bisa diambil kesimpulan bahwa media yang dikembangkan layak digunakan dalam pembelajaran didalam kelas karena rata-rata siswa memberikan tanggapan positif. 
Tabel 1. Tanggapan Siswa

\begin{tabular}{|c|c|c|c|}
\hline \multirow[t]{2}{*}{ Pernyataan } & \multicolumn{2}{|c|}{$\begin{array}{c}\text { Jumlah } \\
\text { Tanggapan }\end{array}$} & \multirow[t]{2}{*}{ Rata-rata } \\
\hline & $\mathbf{S S}$ & $\mathbf{S}$ & \\
\hline Kemudahan akses media pembelajaran & & 3 & 3,00 \\
\hline Penggunaan kacamata virtual reality mudah & 1 & 2 & 3,30 \\
\hline Bahasa yang digunakan mudah untuk di mengerti & 3 & & 4,00 \\
\hline Animasi planet yang ditampilkan menarik & 3 & & 4,00 \\
\hline $\begin{array}{l}\text { Alat bantu kacamata virtual reality yang digunakan } \\
\text { membuat menarik perhatian }\end{array}$ & & 3 & 3,00 \\
\hline $\begin{array}{l}\text { Video animasi virtual reality mengenai susunan tata surya } \\
\text { cukup menarik }\end{array}$ & 2 & 1 & 3,60 \\
\hline $\begin{array}{l}\text { Animasi planet yang ada membuat rasa ingin belajar } \\
\text { meningkat }\end{array}$ & 2 & 1 & 3,60 \\
\hline $\begin{array}{l}\text { Media video animasi virtual reality ini meningkatkan } \\
\text { antusias dalam pembelajaran }\end{array}$ & 2 & 1 & 3,60 \\
\hline $\begin{array}{l}\text { Memudahkan dalam menganalisa susunan tata surya yang } \\
\text { ada }\end{array}$ & 3 & & 4,00 \\
\hline $\begin{array}{l}\text { Suara dubbing yang ada pada media jelas dan mudah } \\
\text { dipahami }\end{array}$ & 2 & 1 & 3,60 \\
\hline Total & & & 3,57 \\
\hline
\end{tabular}

\section{PEMBAHASAN}

Pada penelitian ini berhasil membuahkan produk berupa virtual reality sebagai media pembelajaran pada materi susunan tata surya. Pengembangan ini memanfaatkan model Sadiman (2010) yang memiliki 9 tahapan dan media ini sudah melalui semua tahapan tersebut. Produk yang dihasilkan sudah menjalani uji kelayakan pada ahli media, ahli materi, dan 3 siswa di sekolah Miftahul Huda Blitar. Pengembangan ini melakukan uji kelayakan media pada seorang dosen Teknologi Pendidikan yang mempunyai pengalaman mengajar mata kuliah media pembelajaran sehingga layak untuk menjadi ahli media di pengembangan ini. Untuk ahli materi pengembangan ini melakukan uji kelayakan pada seoarang guru ilmu pengetahuan alam yang pasti menguasai materi susunan tata surya yang ada di media ini. Sedangkan untuk ujicoba lapangan penelitian ini dilakukan pada 3 siswa di sekolah Miftahul Huda Blitar.

Hasil dari uji kelayakan video virtual reality pada ahli media yang telah dilakukan mendapat respon yang positif. Ahli media memberikan respon positif sebesar $100 \%$ dengan rincian respon SS sejumlah 60\%, tanggapan S sejumlah 40\%, mean 3,6, median 4, dan modus 4. Dengan rincian analisis tersebut dalam pembelajaran bahwa media dapat disimpulkan layak. Akan tetapi ahli media juga memberikan komentar terhadap media ini yaitu sebaiknya pengisi suara dubbing orang yang usianya tidak jauh dari peserta didik yang dituju, wujud yang tidak memiliki kaitan dengan materi lebih baik dihilangkan agar tidak membuat pebelajar bingung dengan materi yang disampaikan, dan lebih baik lagi jika ada kesinambungan waktu dan spatial saat penjelasan materi.

Pada tahapan selanjutnya dilakukan uji kelayakan pada ahli materi yang mendapatkan respon positif sebesar 70\%, dengan respon SS sebesar 40\%, respon S sejumlah 30\%, respon KS sebesar $30 \%$, mean 3,1, median 3, dan modus 4. Ahli materi memberikan tanggapan KS sebanyak 3 item yang pertama "Materi sistem tata surya yang di tampilkan sesuai dengan SK/KD" ahli materi memberi tanggapan KS dikarenakan menurutnya materi yang ada didalam media kurang detail, yang kedua "Animasi virtual reality yang ditampilkan memudahkan penyampaian materi" ahli materi beranggapan kurang setuju karena animasi yang ada dimedia ini kurang mendetail, dan yang ketiga "Materi yang ada sudah sesuai dengan perkembangan" ahli materi memiliki tanggapan KS karena materi yang terdapat di media terlalu umum. Akan tetapi ahli materi juga memberikan komentar untuk media pembelajarannya sudah baik, tetapi untuk materi yang terdapat di media 
adalah materi umum. Jadi lebih baik video virtual reaility tersebut lebih mendetail. Dari tanggapan ahli materi tersebut dalam pembelajaran bahwa media dapat disimpulkan layak.

Kemudian uji kelayakan pada responden yang berjumlah 3 orang mendapatkan hasil respon positif sebesar 100\% dengan rincian mean 3,57, median 4, modus 4, tanggapan SS sebesar $60 \%$, dan respon S sebesar 40\%. Dari tanggapan yang diberikan oleh 3 siswa di sekolah Miftahul Huda Blitar bisa ditafsirkan bahwa siswa merasakan kemudahan dalam pembelajaran ilmu pengetahuan alam materi tata surya dan juga memompa ingin belajar dari siswa meningkat karena ada media pelengkap saat proses pembelajaran. Dari analisis data dalam pembelajaran bahwa media dapat disimpulkan layak.

Setelah melalui beberapa uji kelayakan tersebut bisa dikatakan bahwa dalam pembelajaran media yang dikembangkan layak. Akan tetapi media ini juga masih memiliki kekurangan seperti materi yang dimunculkan kurang mendetail. Pentingnya penyajian materi yang cocok dengan pebelajar serta keefektifan dan penekanan dalam mempersembahkan penjelasan materi pokok atau inti, juga menggunakan bahasa yang mudah dimengerti oleh siswa tetapi jika memang ada bahasa istilah yang digunakan sebaiknya menyesuaikan dengan karakteristik siswa (Laksana, 2014). IPA pada asasnya memiliki empat unsur, yang pertama sikap, yang kedua proses, yang ketiga produk, dan yang keempat aplikasi. Dari semua unsur tersebut tidak bisa terpisahkan karena sudah menjadi ciri dari IPA. Dalam proses pembelajaran di sekolah unsur-unsur tersebut diharapkan muncul agar tidak ada ciri dari IPA yang hilang sehingga pebelajar dapat merasakan pembelajaran yang menyeluruh seperti menganalisa gejala jagat raya yang terjadi dan dapat menemukan fakta-fakta yang ada saat ini (Mahmudah, 2017). Pada pembelajaran saat ini diperlukan media yang dapat menopang pembelajaran IPA, media pembelajaran ialah perabot yang berguna untuk menyalurkan amanah atau amanat dari pembelajar kepada pebelajar agar memompa kemauan belajar pebelajar meningkat dan terpukau pada pelajaran (Tafonao, 2018). Meningkatkan kemauan belajar merupakan salah satu tujuan dari penelitian pengembangan ini, karena memompa kemauan belajar peserta didik adalah faktor yang bisa mempengaruhi hasil pembelajaran yang ingin digapai dari tujuan pembelajaran itu.

Menyiapkan pembelajaran tata surya yang dapat membuat pebelajar terpukau, memberi kemudahan terhadap pebelajar dalam proses pembelajaran, dan meningkatkan kemauan belajar siswa. Menarik pandangan pebelajar dalam pembelajaran ini bisa dilakukan dengan memanfaatkan media pembelajaran yang pebelajar belum pernah mengoperasikannya (Andriyani, 2017). Kemenarikan tersebut bisa diwujudkan dalam media yang dikembangkan ini yakni pengembangan virtual reality sebagai media pembelajaran sistem tata surya. Dengan tujuan pembelajaran yang mengharuskan pebelajar bisa mendeskripsikan dan menganalisa susunan tata surya sehingga media video virtual reality bisa membantu. Video virtual reality ini menampilkan objek susunan tata surya yang bisa membuat si pengguna seperti berada dilingkungan luar angkasa (Randi, 2017). Video virtual reality yang di upload ke youtube ini berjenis virtual reality 360 yang memudahkan pengguna dalam mengakses media ini hanya harus memiliki koneksi internet (Hermawan, 2016). Video virtual reality yang berisi susunan tata surya ini bisa dinikmati dengan memanfaatkan alat bantu kacamata virtual sehingga pengguna merasakan suasana virtual reality yang telah dibuahkan oleh pengembang. Kacamata virtual reality memang memiliki fungsi membantu mempersembahkan kesan virtual reality. Cara penggunaan kacamata virtual reality ini cukup mudah hanya dengan memasangkannya pada handphone kemudian memutarkan kepala ke kanan, ke kiri, ke atas, dan ke bawah dengan begitu sensasi virtual reality ini. Handphone yang bisa dimanfaatkan untuk penjalanan media ini harus sudah ada gyroscope (Fernandito et al., 2019). 
Pengembangan video virtual reality sistem tata surya ini selain membutuhkan kacamata virtual reality ini juga membutuhkan handphone. Dengan memanfaatkan handphone media bisa digunakan atau di akses dimana saja yang berefek pebelajar merasa nyaman dan gampang dalam pembelajaran (Nurhidayat et al., 2019). Penelitian pengembangan virtual sistem tata surya ini mempunyai kelebihan bisa digunakan dirumah untuk belajar mandiri, kondisi pandemi saat ini media yang dikembangkan serasi dengan pembelajaran yang saat ini dilaksanakan daring. Selain itu media virtual reality juga bisa meningkatkan kemauan peserta didik untuk belajar karena dengan memanfaatkan video virtual reality siswa dapat merasakan lingkungan susunan tata surya yang ada di dalam pengembangan ini (Mambu et al., 2019).

\section{SIMPULAN}

Berdasarkan penelitian pengembangan virtual reality sebagai media pembelajaran sistem tata surya ini dapat di ambil kesimpulan bahwa didalam pembelajaran media layak digunakan. Di karenakan mendapat respon yang positif saat uji kelayakan pada ahli media dan ahli materi, serta saat ujicoba terhadap pebelajar juga mendapat respon yang positif. Akan tetapi media yang dihasilkan ini juga masih memiliki kekurangan seperti saran dari ahli media yaitu suara dubbing lebih bagus orang yang seumuran dengan sasaran pebelajar dan menghilangkan bagian yang tidak ada kaitan dengan inti materi yang disampaikan. Sedangkan dari ahli materi memberikan saran akan lebih bagus lagi jika video virtual reality lebih mendetail.

\section{DAFTAR RUJUKAN}

Andriyani, I. P. (2017). Pengembangan Video Pembelajaran Pada Program Bina Diri Menggosok Gigi Untuk Siswa Tunagrahita Kelas III di Sekolah Pendidikan Khusus Negeri Karanganyar Kebumen. Universitas Negeri Semarang.

Ariyanto, M. (2016). Peningkatan Hasil Belajar IPA Materi Kenampakan Rupa Bumi Menggunakan Model Scramble. Profesi Pendidikan Dasar, 3(2), 134-140.

Fadhli, M. (2016). Pengembangan media pembelajaran berbasis video kelas iv sekolah dasar. Jurnal Dimensi Pendidikan Dan Pembelajaran, 3(1), 24-33.

Fernandito, D., Sambul, A. M., \& Sugiarso, B. A. (2019). Aplikasi Virtual Reality Untuk Edukasi Musik. Jurnal Teknik Informatika, 14(3), 313-320.

Hermawan, I. (2016). Katalog Virtual Reality E-Tourism Berbasis Video 360 Sebagai Konten Digital Kreatif Bagi Media Simulasi Profil Destinasi Wisata. Prosiding Sentrinov (Seminar Nasional Terapan Riset Inovatif), 2(1), 478-485.

Indriyani, L. (2019). Pemanfaatan media pembelajaran dalam proses belajar untuk meningkatkan kemampuan berpikir kognitif siswa. Prosiding Seminar Nasional Pendidikan FKIP, 2(1), $17-26$.

Kelana, J. B., \& Pratama, D. F. (2019). Bahan ajar IPA berbasis literasi sains. Bandung: Lekkas.

Laksana, D. N. L. (2014). Profil pemahaman konsep IPA guru-guru kelas sekolah dasar di Kabupaten Ngada. Jurnal Ilmiah Pendidikan Citra Bakti, 1(1), 15-26.

Luhulima, D. A., Degeng, N. S., \& Ulfa, S. (2018). Pengembangan Video Pembelajaran Karakter Mengampuni Berbasis Animasi Untuk Anak Sekolah Minggu. JINOTEP (Jurnal Inovasi Dan Teknologi Pembelajaran): Kajian Dan Riset Dalam Teknologi Pembelajaran, 3(2), 110120.

Mahmudah, L. (2017). Pentingnya pendekatan keterampilan proses pada pembelajaran IPA di Madrasah. ELEMENTARY: Islamic Teacher Journal, 4(1).

Mambu, J. Y., Wahyudi, A. K., \& Hezky, G. (2019). “Jump”: Game Simulasi Olahraga Berbasis Virtual Reality Dengan Sensor Accelerometer. Nutrix Journal, 3(2), 58-62. 
Megawanti, P. (2015). Meretas Permasalahan Pendidikan Di Indonesia. Formatif: Jurnal Ilmiah Pendidikan MIPA, 2(3).

Mihelj, M., Novak, D., \& Beguš, S. (2014). Virtual reality technology and applications.

Nisrina, N., Gunawan, G., \& Harjono, A. (2017). Pembelajaran kooperatif dengan media virtual untuk peningkatan penguasaan konsep fluida statis siswa. Jurnal Pendidikan Fisika Dan Teknologi, 2(2), 66-72.

Noviana, Y. (2017). Sikap Ilmiah Siswa Kelas V Dalam Pembelajaran IPA SK Mengidentifikasi Cara Makhluk Hidup Menyesuaikan Diri Dengan Lingkungan di MI Ma'arif NU 01 Pasir Kulon Karanglewas Banyumas. IAIN.

Nurhidayat, B., Wedi, A., \& Praherdhiono, H. (2019). Pengembangan Multimedia Mobile Learning Berbasis Smartphone Android Materi Huruf Madura untuk SD Negeri 1 Perante Kabupaten Situbondo. Jurnal Inovasi Teknologi Pembelajaran, 6, 103-110.

Pratama, R. A., Ulfa, S., \& Kuswandi, D. (2018). Mobile Learning Berbasis Game Based Learning Pelajaran Matematika Pokok Bahasan Bangun Ruang Sisi Datar. Jurnal Pendidikan: Teori, Penelitian, Dan Pengembangan, 3(6), 771-777.

Randi, A. (2017). Pemanfaatan Teknologi Virtual Reality sebagai Media Pembelajaran Interaktif untuk Sistem Tata Surya Berbasis Android. Universitas Islam Negeri Alauddin Makassar.

Sadiman, A. S., Rahardjo A, Haryono A, \& Rahardjito. (2010). Media Pendidikan: Pengertian, Pengembangan, dan Pemanfaatannya. Cetakan ke-13. PT. Raja Grafindo Persada.

Sihkabuden. (2011). Media Pembelajaran. Universitas Negeri Malang.

Sinambela, M. B. W., Soepriyanto, Y., \& Adi, E. P. (2018). Taman Peninggalan Sejarah Berbasis Virtual Reality. Jurnal Kajian Teknologi Pendidikan, 1(1), 7-12.

Suwastika, I. W. K. (2018). Pengaruh e-learning sebagai salah satu media pembelajaran berbasis teknologi informasi terhadap motivasi belajar mahasiswa. Jurnal Sistem Dan Informatika (JSI), 13(1), 1-5.

Syafril, R. S. (2019). Penerapan Sederhana Virtual Reality Dalam Presentasi Arsitektur. Nalars, 19(1), 29-40.

Tafonao, T. (2018). Peranan media pembelajaran dalam meningkatkan minat belajar mahasiswa. Jurnal Komunikasi Pendidikan, 2(2), 103-114.

Zuli, F. (2018). Rancang Bangun Augmented Dan Virtual Reality Menggunakan Algoritma Fast Sebagai Media Informasi 3D Di Universitas Satya Negara Indonesia. Jurnal Algoritma, Logika Dan Komputasi, 1(2). 